\title{
Changes in Mechanical Properties of Metallic Pipes Subjected to Accelerated Corrosion Test
}

\author{
Thien Dinh Hoang ${ }^{1 *}$, Balázs Kovács¹, Tamás Madarász¹, Imre Czinkota² \\ ${ }^{1}$ Institute of Environmental Management, Faculty of Earth Science and Engineering, University of Miskolc, H-3515 Miskolc, \\ Egyetemváros, P. O. B. 21, Hungary \\ 2 Department of Soil Science and Agricultural Chemistry, Faculty of Agricultural and Environmental Science, Szent István \\ University, 2100 Gödöllő, 1 Páter Károly utca, Hungary \\ * Corresponding author, e-mail: hgthien@uni-miskolc.hu
}

Received: 29 August 2020, Accepted: 25 September 2020, Published online: 02 December 2020

\begin{abstract}
One of the most significant current discussions in fluid transport industry is how to prolong the service life of a metallic pipeline system under severe physical and chemical conditions. Electrochemical corrosion is a persistent problem, causing material degradation and sometimes resulting in serious consequences. Here more than 150 three-point bending tests were done on 82 corroded carbon steel pipes to examine their remaining strength. The current work proposes an artificial protocol to accelerate the electrochemical corrosion of ferrous tubes in a controllable system and analyzed correlations between removed iron mass, the depth of corroded sites, and the deterioration in the mechanical properties of the sample pipes. Based on these correlations, a rough estimate for the retirement life of pipelines is put forward as a referable option.
\end{abstract}

Keywords

electrochemical corrosion technique, metallic pipeline, strength degradation, corroded patterns, bend test

\section{Introduction}

The crippling effect of corrosion on buried ferrous pipeline transportation systems is becoming increasingly difficult to ignore. Endless cycles of wetting and drying tend to induce a slow process of coating detachment [1], which enables the growth of corrosion or even enlarges existing leakages. In an aging system [2], once ruptures appear, the fluid and gas flowing through these distribution networks will spread out, resulting in structural failure, intermittent supply, product losses [2], environmental damage, and even tragedies. Numerous reports over recent decades have shown an immense amount of infrastructure degradation owing to this long-standing problem [3-5]. Meanwhile, the most recent statistics in Hungary indicate that on the national level, ferrous pipes account for $6 \%$ of the water supply system [2]; however, in major cities (e.g. the capital city), this figure can reach $32 \%$ [6].

An artificial corrosion system applied over a carbon steel surface was designed to deliberately and quickly induce corrosive damage to the sample pipes at given positions on their exteriors in a short time [7]. In the past, this technique has been utilized as a quality control tool for the installation of pipelines. This is a fully controllable system since it can be adjusted to any testing conditions, such as exposure time, types of electrolytes, types of metallic pipes, etc. Furthermore, the rate of corrosion of this synthetic system is of very high magnitude compared to the corrosion found in slightly acidic soils [8].

With similar aims, several researchers have reported on the chemical examination of pipes and their corresponding analysis. In 2010, Sadeghi Meresht et al. [9] used metallographic studies to determine the disbonded polyethylene tape coating on the external surface as the prime cause for stress corrosion cracking in the pipeline steel in northern regions of Iran. Li et al. [10] suggested selecting suitable substitute alloys after discussing the main causes of the corrosion backed by observed microstructures and mass loss experiments. Visual evidence and the results of chemical and metallurgical analyses conducted in the vicinity were employed to examine failure $[11,12]$. Taking advantage of the finite element method and neural networks, a considerable amount of literature using numerical simulation has been published on the failure 
of pipeline transportation systems [13-18]. Based on the ability to resist hydrostatic pressure, Alamilla et al. [19] took the material strength and wall-thickness loss into account to validate the ductile mechanism of mechanical failure in straight pipes. Tsuji and Meshii [20] performed a series of similar experiments to examine the effects of inner defection and faulty directions created on pipe samples. Other mechanical models have been used to observe the failure of corroded pipes; e.g. internal pressure testing with a hydrostatic test can be found in [21-23]. Inadequate mechanical behavior examination can be seen [24], knowledge in this area has been gained only by small-scale studies (7 specimens), particularly not corroded samples, not to mention the pre-selected circumferential or longitudinal degradation of specimens.

Carbon steel pipes in accordance with European Standard EN 10220:2002 [25] are usually used in fluid transportation systems. In this study, we first induce corrosion in 82 ferrous pipes of these types, and then test the remaining strength with three-point bending tests in 153 testing locations along the pipes. The aim of the investigation is to predict the effect of corrosion on pipe strength in order to estimate the remaining life in service of ferrous pipelines working in corrosive environments.

\section{Material and experimental setting}

To determine corroded pipes' remaining strength, mechanical testing technique involving three-point bending at their weakest spots was employed with improvised loading equipment. Corrosion process in the ferrous pipes by immersion is described below in Sub-subsection 2.2.1. Removed iron mass was computed, and the defection depth was measured. Having more than one group of corrosive spots on each tube sample allows us to be able to produce 153 bending results from 82 electrochemically corroded pipes.

\subsection{Material}

According to European Standard EN 10220:2002 [25], in terms of physical characteristics, the pipe specimens used in this research have an outside diameter of $21.3 \mathrm{~mm}$, $1.8 \mathrm{~mm}$ wall thickness, and $0.866 \mathrm{~kg} / \mathrm{m}$ of mass per unit length, and are free of any coatings, galvanic or other surface treatment. Mechanical properties of these kinds of electric welded non-alloy steel tubes with specified low-temperature properties are given in Tables 1 and 2, obtained from European Standard EN 10217-4:2002 [26].

\subsection{Experimental settings and operations}

\subsubsection{Corrosion test}

The controlled acceleration system used here enables us to artificially corrode ferrous pipe at given positions actively within a considerably shorter time than realistic conditions (Fig. 1). In order to create an identical working condition similar to the saline water surroundings under the sea floor, an inert chamber was filled with a $3.5 \%$

Table 1 Mechanical properties at room temperature for wall thickness $T$ up to and including $16 \mathrm{~mm}$ [26]

\begin{tabular}{|c|c|c|c|c|c|}
\hline \multicolumn{3}{|l|}{ Steel grade } & \multicolumn{3}{|c|}{ Tensile properties } \\
\hline \multirow[t]{2}{*}{ Steel name } & \multirow[t]{2}{*}{ Steel number } & \multirow{2}{*}{$\begin{array}{l}\text { Upper yield strength or proof strength } \\
\qquad R_{e H} \min \text { or } R_{p p .2} \text { min } \\
\mathrm{MPa}^{*}\end{array}$} & \multirow{2}{*}{$\begin{array}{c}\text { Tensile strength } \\
\qquad R_{m} \\
\mathrm{MPa}^{*}\end{array}$} & \multicolumn{2}{|c|}{$\begin{array}{l}\text { Elongation }{ }^{\mathrm{a}} \\
A \min \\
\%\end{array}$} \\
\hline & & & & $l$ & $t$ \\
\hline $\mathrm{P} 215 \mathrm{NL}^{\mathrm{b}}$ & 1.0451 & 215 & 360 to 480 & 25 & 23 \\
\hline P265NL & 1.0453 & 265 & 410 to 570 & 24 & 22 \\
\hline
\end{tabular}

a $l=$ longitudinal, $t=$ transverse

${ }^{\mathrm{b}}$ For wall thickness $T \leq 10 \mathrm{~mm}$

${ }^{*} 1 \mathrm{MPa}=1 \mathrm{~N} / \mathrm{mm}^{2}$

Table 2 Chemical composition (cast analysis) ${ }^{\mathrm{a}}$, in \% by mass [26]

\begin{tabular}{|c|c|c|c|c|c|c|c|c|c|c|c|c|c|c|c|}
\hline \multirow{2}{*}{$\begin{array}{l}\text { Steel grade } \\
\text { Steel name }\end{array}$} & \multirow[b]{2}{*}{$\begin{array}{l}\text { Steel } \\
\text { number }\end{array}$} & \multirow{2}{*}{$\begin{array}{c}\mathrm{C} \\
\operatorname{Max}\end{array}$} & \multirow{2}{*}{$\begin{array}{c}\mathrm{Si} \\
\mathrm{Max}\end{array}$} & \multicolumn{2}{|c|}{$\mathrm{Mn}$} & \multirow{2}{*}{$\begin{array}{c}\mathrm{P} \\
\text { Max }\end{array}$} & \multirow{2}{*}{$\begin{array}{c}\mathrm{S} \\
\operatorname{Max}\end{array}$} & \multirow{2}{*}{$\begin{array}{l}\mathrm{Cr} \\
\mathrm{Max}\end{array}$} & \multirow{2}{*}{$\begin{array}{l}\text { Mo } \\
\text { Max }\end{array}$} & \multirow{2}{*}{$\begin{array}{l}\mathrm{Ni} \\
\mathrm{Max}\end{array}$} & \multirow{2}{*}{$\begin{array}{l}\mathrm{Al}_{\text {total }} \mathrm{b} \\
\mathrm{Max}\end{array}$} & \multirow{2}{*}{$\begin{array}{l}\mathrm{Cu}^{\mathrm{c}} \\
\mathrm{Max}\end{array}$} & \multirow{2}{*}{$\begin{array}{l}\mathrm{Nb} \\
\mathrm{Max}\end{array}$} & \multirow{2}{*}{$\begin{array}{c}\mathrm{Ti} \\
\operatorname{Max}\end{array}$} & \multirow{2}{*}{ V } \\
\hline & & & & Min & Max & & & & & & & & & & \\
\hline P215NL & 1.0451 & 0.15 & 0.35 & 0.40 & 1.20 & 0.025 & 0.020 & 0.30 & 0.08 & 0.30 & 0.020 & 0.30 & 0.010 & 0.03 & 0.02 \\
\hline P265NL & 1.0453 & 0.20 & 0.40 & 0.60 & 1.40 & 0.025 & 0.020 & 0.30 & 0.08 & 0.30 & 0.020 & 0.30 & 0.010 & 0.03 & 0.02 \\
\hline
\end{tabular}

a Elements not included in this Table shall not be intentionally added to the steel without the agreement of the purchaser, except for elements which may be added for finishing the cast. All appropriate measures shall be taken to prevent the addition of undesirable elements from scrap or other materials used in the steel making process.

${ }^{\mathrm{b}} \mathrm{Al} / \mathrm{N} \geq 2$, if nitrogen is fixed by niobium, titanium or vanadium the requirement for $\mathrm{Al}_{\text {tot }}$ and $\mathrm{Al} / \mathrm{N}$ do not apply.

${ }^{c}$ Option 2: In order to facilitate subsequent forming operation, an agreed maximum copper content lower than indicated and an agreed specified maximum tin content shall apply. 


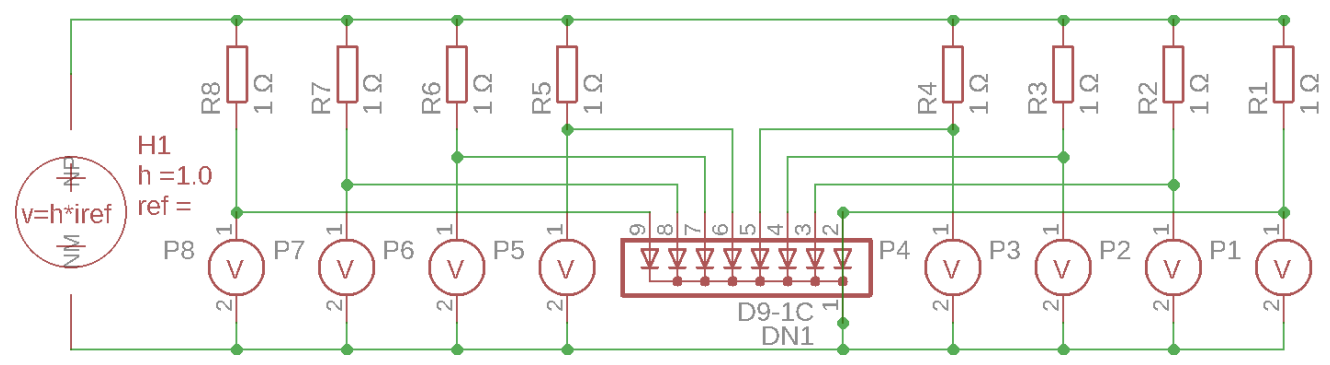

Fig. 1 Schematic diagram of the artificially controlled setting of corrosion

sodium chloride concentration solution, which also works as the electrolyte of an electrical system (Fig. 2). As a means to support the electrochemical process, a fixed set of four identical metallic pipes, which are made of a metal of higher position than iron in the galvanic series (i.e. copper), playing cathodic roles in the electrolytic corrosion, is attached tightly to a plastic frame.

Eight pipe samples were scrubbed vigorously using acetone-absorbed cleaning tissue to get rid of any industrial oil left on their surfaces during the production process. The bottom end of each pipe is filled with silicon so as to prevent the coating liquid and electrolyte from entering the pipe in the coating and testing process. Except for some bare surface spots of circular shape measured $6.3,8.45$, or $10 \mathrm{~mm}$ in diameter, the entire exteriors of these eight specimens were carefully painted. The number and position of these spots will be shown in Sub-subsection 2.2.2. A total of 82 samples were prepared to conduct the corrosion experiment.

During the experiment, metallic corrosion naturally occurs in the electrochemical process as a series of reduction-oxidation reactions. The steel tubes attached to the positive side of the power supply are being concurrently corroded and oxidized. They, therefore, release electrons, form positively-charged metal ions, and become sacrificial anodes with small cavities on the pipe surface at given spots. In the meantime, free electrons move to the cathodes, which are attached to the negative side of the power supply before automatically combining with positively-charged hydrogen ions available in the solvent to generate hydrogen molecules.

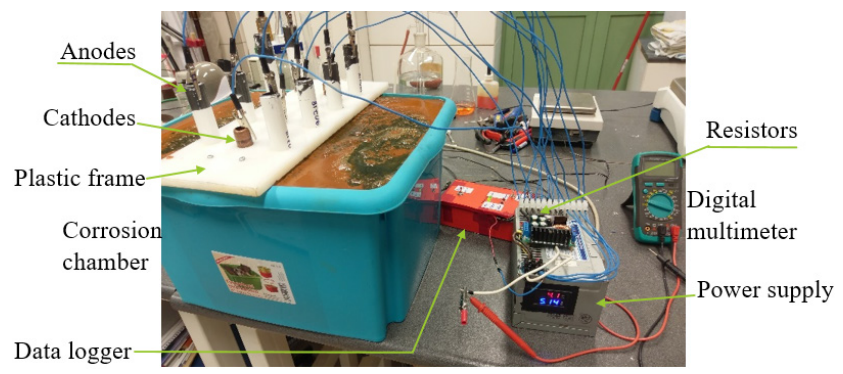

Fig. 2 The artificial corrosion device setup in reality
Anodic process is:

$\mathrm{Fe}(s) \rightarrow \mathrm{Fe}^{2+}(a q)+2 e^{-\circ} E^{o}=-0.45 \mathrm{~V}$.

Cathodic process is:

$\mathrm{O}_{2}(g)+4 \mathrm{H}^{+}(a q)+4 e^{-} \rightarrow 2 \mathrm{H}_{2} \mathrm{O} \quad E^{o}=1.23 \mathrm{~V}$.

A set of eight indistinguishable resistors (1 Ohm) in combination with chronological voltage data from measurement was used to compute eight parallel currents running through eight anode-cathode pairs.

For the estimation of iron mass released during the testing process, a mathematical combination of measuring time, computed electric current, and Faraday's law was employed to obtain the most accurate result. Because we know that the $\mathrm{Fe}^{+2}$ cation formed in the oxidation process releases two electrons to the electrode during the dissolution, the formula applied is (see also Fig. 3):

$m=\frac{M}{F \times z} \times \int_{o}^{T} I \mathrm{dt}$,

where:

- $m$ : mass of iron entering the solution [mg]

- $I$ : the current [mA], ranging from around $200 \mathrm{~mA}$ to approximately $1000 \mathrm{~mA}$, depending on exposing

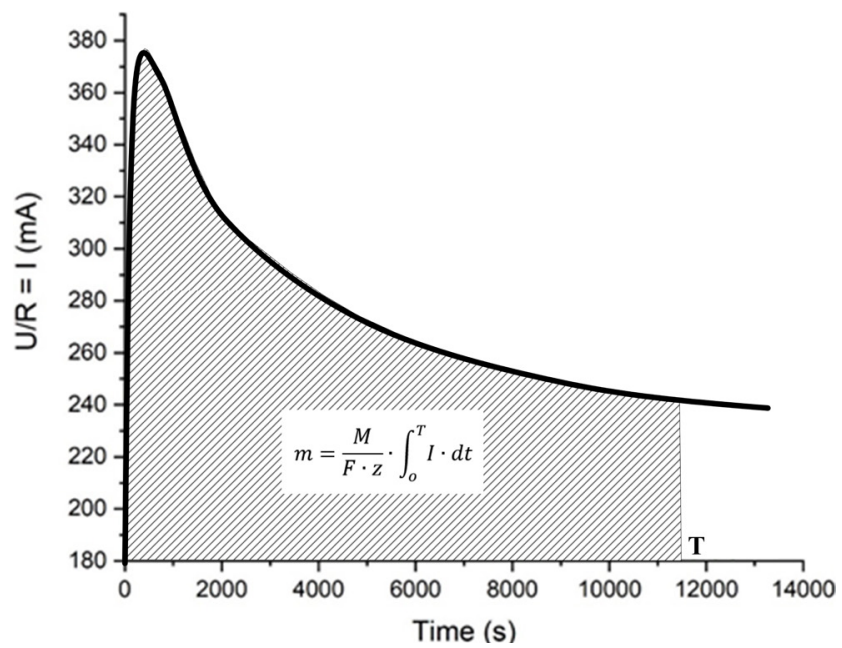

Fig. 3 General concept of removed iron mass calculation 
areas. The currents are derived from the $U$ voltage measured across the $R=1 \Omega$ resistor

- $T$ : total elapsed time [sec]

- $M$ : the relative atomic mass of iron, $56\left[\mathrm{~g} \mathrm{~mol}^{-1}\right]$

- $F$ : Faraday constant, $96500\left[\mathrm{C} \mathrm{mol}^{-1}\right]$

- $z$ : ion charge, 2 [-].

The dissolution of the metal ions at the anodes may probably diffuse into the solution, becoming hydrated as all hydrogen molecules at the cathode will float and vaporize out of the electrolyte. Obviously, there is also a slight possibility that the released metal ions may gather at the anode to create a solid protective barrier and inhibit further corrosion. Thus, this artificial electrochemical process is extended as long as needed to reach our goal of testing.

$\mathrm{Fe}^{2+}+2(\mathrm{OH})^{-} \rightarrow \mathrm{Fe}(\mathrm{OH})_{2}$

The other part reacts with the oxygen diffused from the atmosphere, settling to the bottom of the chamber, conforming to the following equation:

$$
\begin{aligned}
& 4 \mathrm{Fe}^{2+}(a q)+\mathrm{O}_{2}(g)+(2+4 x) \mathrm{H}_{2} \mathrm{O} \\
& \rightarrow 2 \mathrm{Fe}_{2} \mathrm{O}_{3} \times x \mathrm{H}_{2} \mathrm{O}+4 \mathrm{H}^{+}(a q) .
\end{aligned}
$$

\subsubsection{Bending test}

In most cases, the pipelines work under high internal pressure and are bent downwards rather than otherwise. As a result, either breakage or the downward bending effect or both - typically occurs at the thinnest, weakest position of the pipe wall, which is prone to happen at a damaged segment on the bottom side. It should be noted that, since the pipe samples were all made by the electric welding process, there is always a lengthwise seam, which is actually an inward elevated thread of the pipe material inside the pipe wall. Hence, in order to attain the ultimate goal of examining the remaining strength in the corroded pipes in the worst case (safety factor was taken into account), three-point bending experiments were conducted with the loading point located at the ruined segment on this tangent line in the direction of the bend, where the corroded site lies underneath. Groups of 1, 2, or 3 corroded spots were located at the halfway point of the $12 \mathrm{~cm}$ span between the two supporting points of the bending machine. Depending on the testing demand, these spots could stand alone or in groups of 2 or 3, in either longitudinal (along) or circumferential (cross) direction. Three size options for the spot (small, medium, large) and 3 degrees of degradation (native, corrosion in gypsum, saline water) were chosen, resulting in various testing pattern outcomes (Fig. 4).

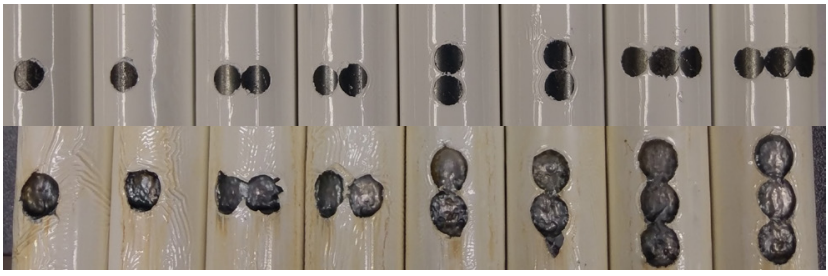

Fig. 4 Pattern options resulted from various ways of combinations of factors

A dial gauge indicator was used to measure the depth of the damaged sites to evaluate the degree of degradation due to corrosion (Fig. 5). With a $0.01 \mathrm{~mm}$ reading interval, this instrument yields reasonably precise results. Without the support of high-resolution microscopy technique, only fairly reliable results of width and length measurements can be expected. Thanks to the caliper's accuracy of $0.1 \mathrm{~mm}$ tick spacing, the width, and length of corrosive area can be measured in terms of circumference and length, respectively. Apart from the depth and size of corrosive area, the mass of the specimens was computed. The decrease in the mass of each pipe will be interpreted later in Subsection 3.1.

To conduct the three-point bending test on the pipes, a computer-controlled servo-hydraulic actuator of $150 \mathrm{kN}$ capacity with built-in transducer 50-C1400/8 was employed. The aggregating applied load is quantified directly, exploiting a strain gauge based load cell of 20 tons dynamic capacity linked with the actuator. A de signal conditioner module in the servo-hydraulic control console ADVANTEST-9

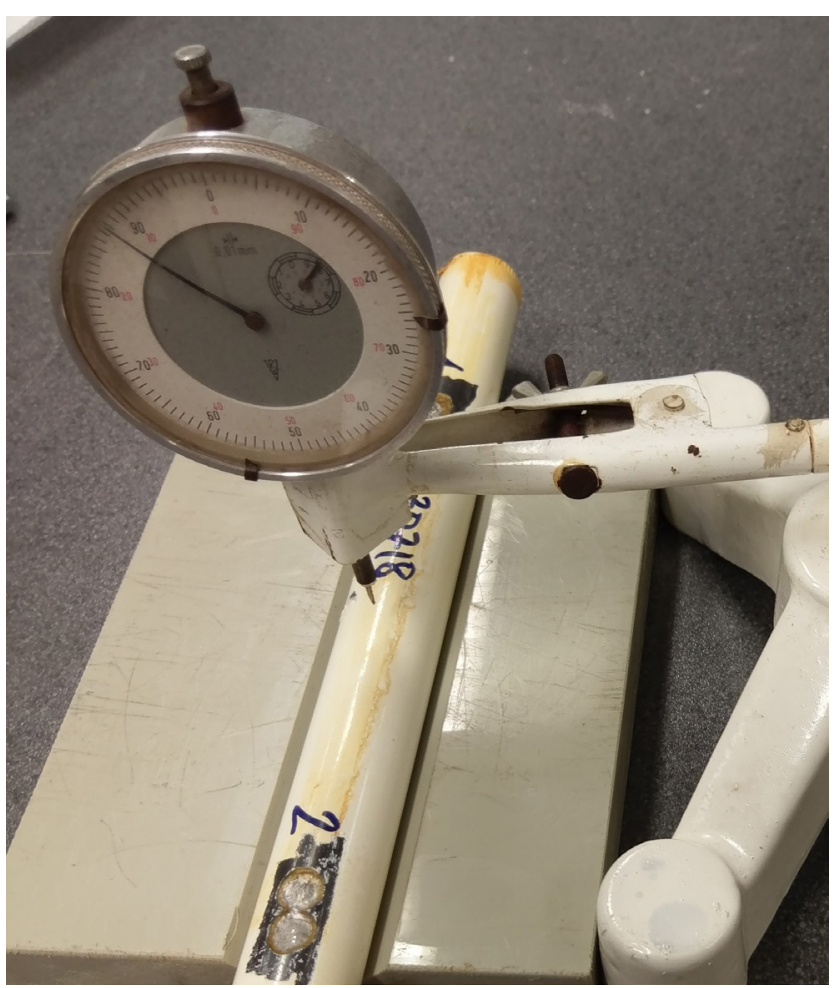

Fig. 5 Depth measurement 
conditions the load cell output. Attached right below this moving part is a horizontally cylindrical solid steel segment that plays the role of loading point from the top. Two other similar rolling steel segments take charge of the two supporting points on the bottom side. All three critical components are free to rotate around their own axes, which were fixed onto a strong steel frame (Fig. 6).

The pipe samples are placed symmetrically below one loading point and above two supporting points in the indicated position. The chosen span of $12 \mathrm{~cm}$ is rigidly fixed between two horizontally longitudinal axes of the cylindrical supporting points. The hydraulic engine gradually pushes the horizontally longitudinal axis of the cylindrical loading point downward vertically, driving forces onto the cross section of the tube at which the corroded area is located on the inverted line. Concurrently, a dial gauge indicator is employed to take displacement measurements. These data are then delivered directly via signal cables to the built-in computer, where compatible pre-installed software records the data and sketch them out in two plots. In the meantime, the screen presents the two relationships, which are load-displacement and time-displacement in visual form. A set of testing parameters is designated in advance, which can be seen in Fig. 7.

A constant loading speed of $3 \mathrm{kN} / \mathrm{min}$ and unloading phase in turn allows the pipes to deform and reform gradually and show a period of fatigue and finally collapse at their weakest points. The dial gauge indicator was installed onto the frame at a good contacting posture.

\section{Results}

\subsection{Corrosion test}

Immersion time, working media, characteristics of desired corrosion sites, temperature conditions, and chemical composition of the tubes are all theoretical considerations that must be taken into account. Quantitative demonstrations of similarly empirical data, which are somewhat analogous in statistical correlation, were performed in groups (Fig. 8). In this case, another archetypal parameter is the removed iron mass (Fig. 9). This parameter excludes the impact of spot dimension by exhibiting the practically overlapped falling pattern in the value of removed iron mass. The gradient developed from the best-fit line of the removed iron mass against time curve provided information concerning the isolation rate of iron in the course of the electrochemical corrosion progress, which is formerly known as a time-independent parameter (Fig. 10):

$i=\frac{m_{t}}{A}$

where:

- $i$ : corrosion intensity or specific removed iron mass $\left[\mathrm{mg} \mathrm{mm}^{-2}\right]$

- $m_{t}$ : the time-lapse mass of iron entering the solution [mg]

- $A$ : the exposed surface area $\left[\mathrm{mm}^{2}\right]$;

$$
v=\frac{\partial m_{n}}{\partial_{t}}
$$

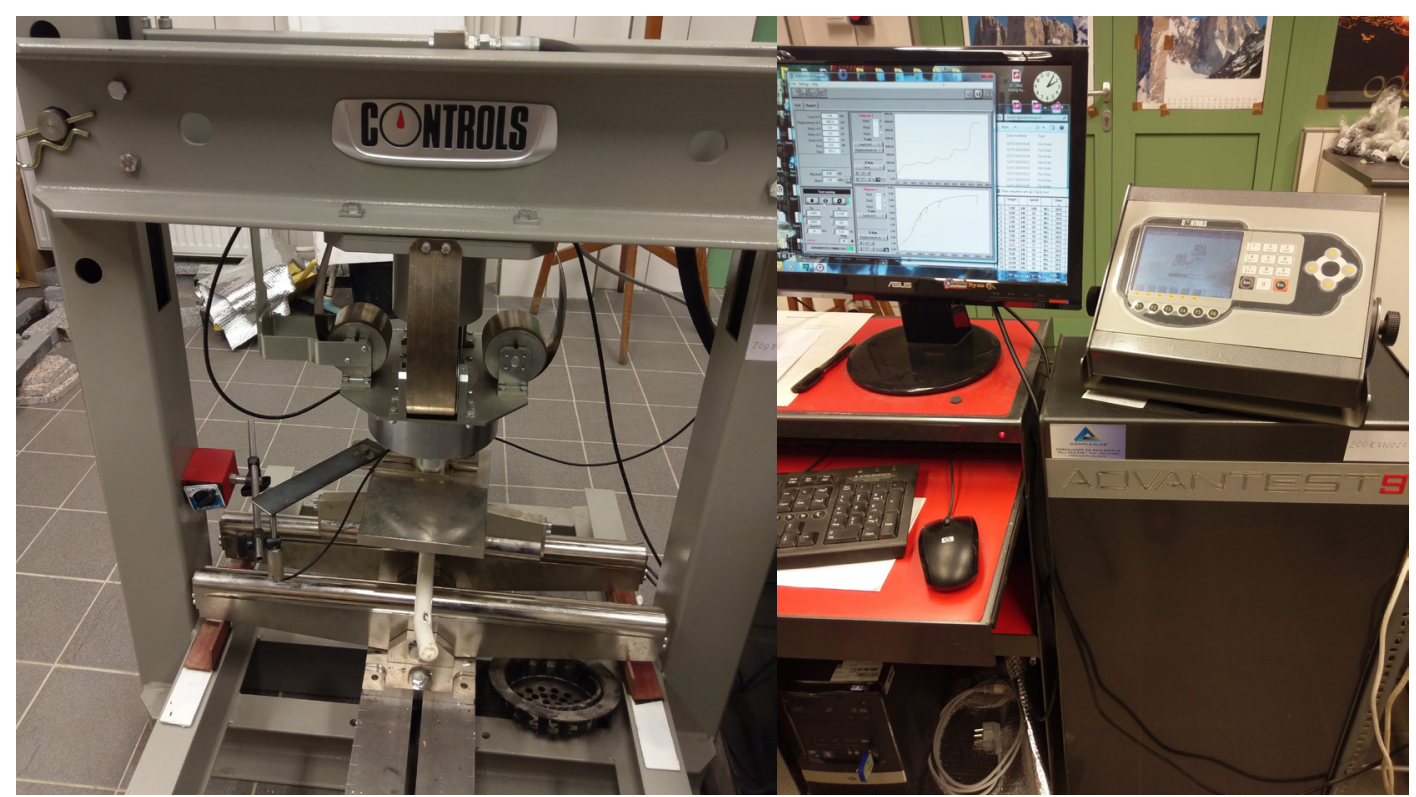

Fig. 6 Picture of the experimental setup and associated built-in software 


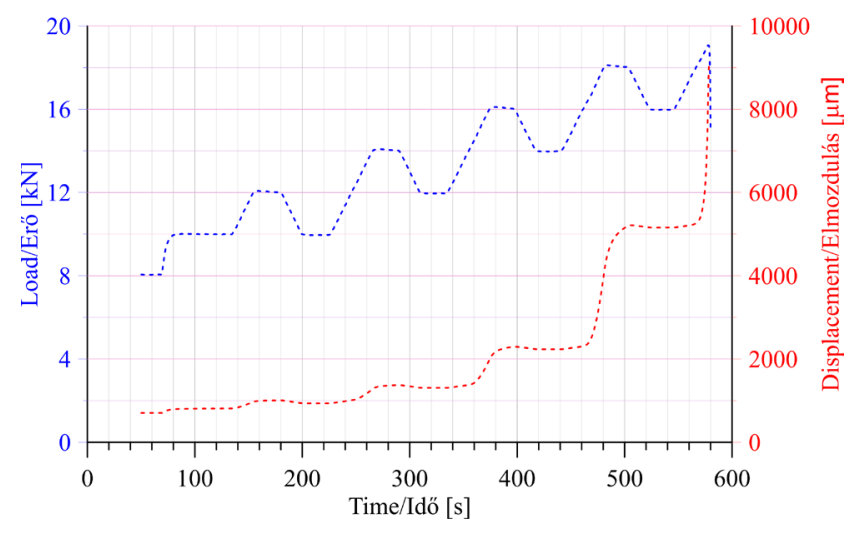

Fig. 7 Load-time and displacement-time curves of a three- point bending test

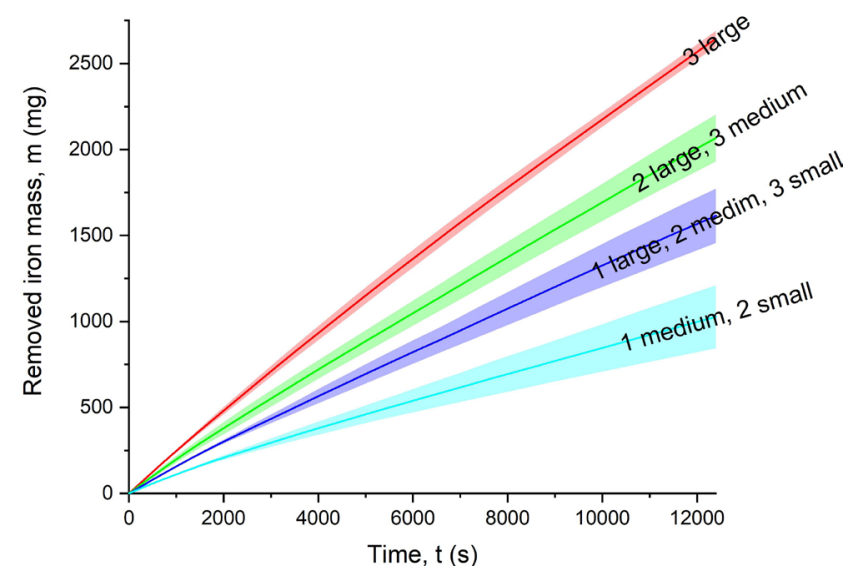

Fig. 8 Common range of removed iron mass versus time for various spot sizes and numbers in the experiments

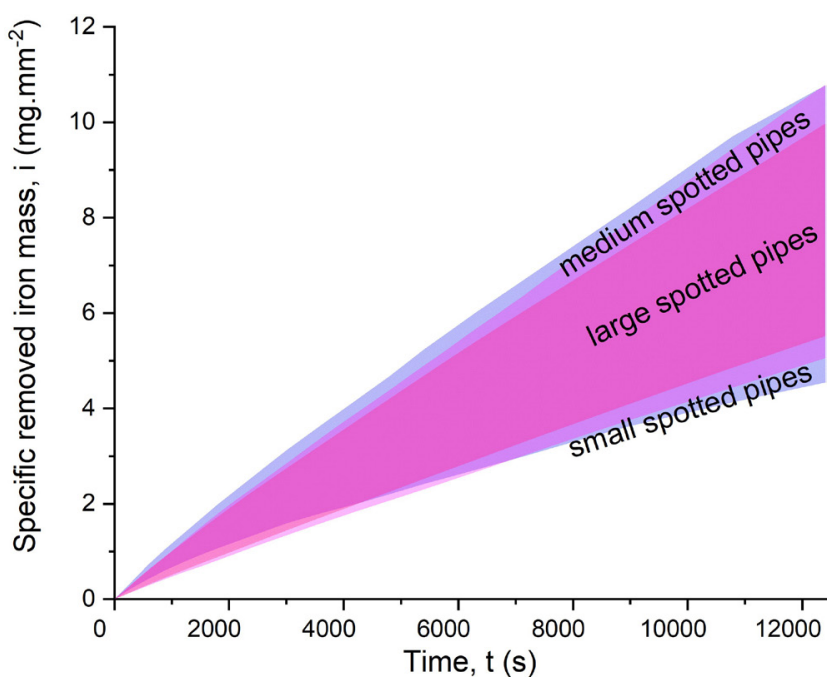

Fig. 9 Common range of specific removed iron mass versus time for various spot sizes in the experiments

where:

- $v$ : the slope value, indicating dissolution rate of iron, $56\left[\mathrm{mg} \mathrm{s}^{-1}\right]$

- $m_{n}$ : net removed iron mass $[\mathrm{mg}]$

- $t$ : time $[\mathrm{sec}]$

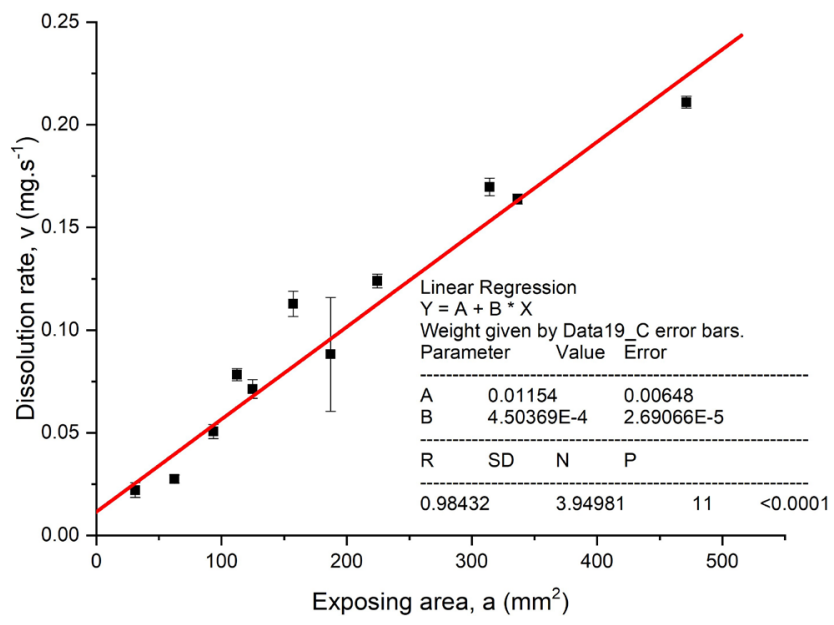

Fig. 10 Removed iron mass on different size spotted pipe in unit of time

$C_{r}=\frac{i}{\partial_{t}}$,

where:

- $C_{r}$ : Corrosion rate $\left[\mathrm{mg} \mathrm{mm}^{-2} \mathrm{~s}^{-1}\right]$.

ANOVA comparative analysis was utilized to check the effect of directional scattering of spots, spot sizes, and working liquid varieties on the corrosion rate of analogous specimens, which conclusively demonstrates the minor and major factors and their statistical correlation (Fig. 11).

Comparative analyses of the corrosion test results indicate that the corrosion intensity (specific iron mass removal) is numerically unrelated to the number, size, or direction of the sites, or to the position of the examined tube in the corrosion chamber. However, it hinges critically upon the electrolyte type (i.e. sodium chloride solution or gypsum suspension). Pipe composition, which was not investigated in this work, is another potential factor.

\subsection{Bending test}

In these series of tests, we also employed the native pipes to have a full adjustment and make them the standard figure to draw analogies with the corroded pipes. As of mechanical rule, at the bending section, ovality could be observed with the distortion of the pipe samples. The rolling supporting points enable specimens to settle without friction. Five parameters in the bending test are examined:

The ultimate (highest) peak force $[\mathrm{kN}]$ is the loading force at which the pipe is totally collapsed, exhibiting either one of the two following signs:

- the unloading does not accompany any recovery;

- or the constant load accompanies a drastic increase in displacement. 

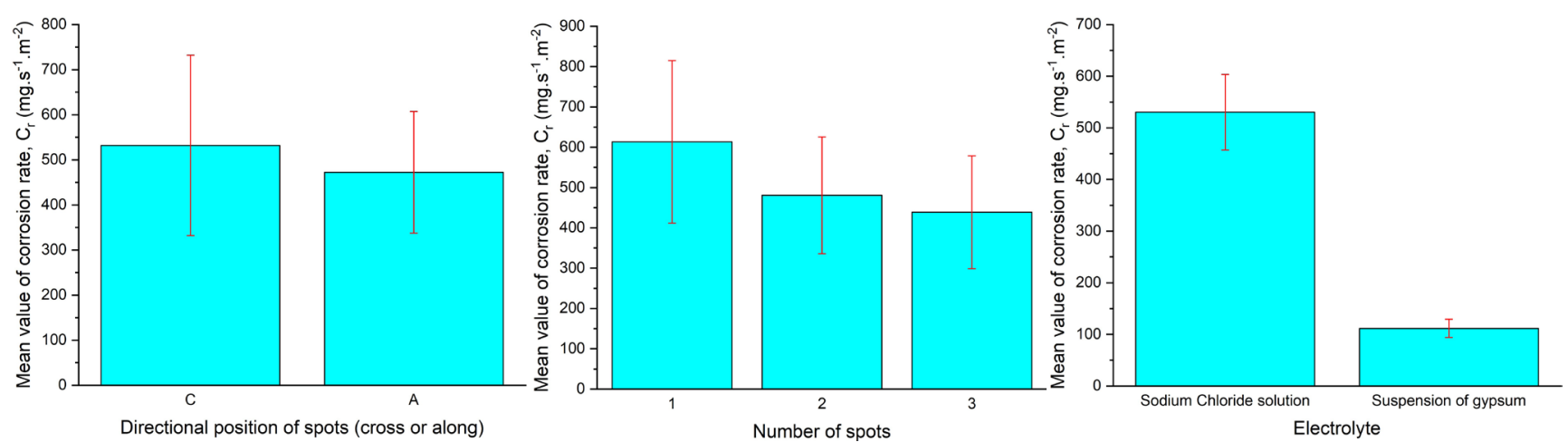

Fig. 11 Difference in corrosion rate referring to different driving factors

Total displacement $[\mu \mathrm{m}]$ : the downward movement of the bending cross-section due to the vertical load.

Slope $[\mathrm{kN} / \mu \mathrm{m}]$ : the ratio in each changing load phase of the loading force and the displacement gaining within this phase only. Therefore, we have Slope 05 or Slope 56 and so on in loading phases from 0 to $5 \mathrm{kN}$, from 5 to $6 \mathrm{kN}$, respectively.

Elapse-Stiffness [N/mm]: the ratio of the highest peak force to the total displacement aggregating up to the moment of reaching this load. Similarly, we examine stiffness after every loading phase from 0 to $5 \mathrm{kN}$, from 5 to $6 \mathrm{kN}$, and so on, with the corresponding names stiffness 05 , stiffness 56 , etc.:

$\sigma=\frac{M}{K}$

where:

- $\sigma$ : Pipe's stiffness [ $\left.\mathrm{kN} \mathrm{mm}^{-1}\right]$

- $M$ : Bending moment at the cross-section of the loading point [ $\mathrm{kN} \mathrm{mm}]$, calculated from Eq. (6);

- $K$ : Shape coefficient $\left[\mathrm{mm}^{3}\right]$; calculated from Eq. (7);

$M=\frac{F \times L}{4}$,

where:

- $F$ : Ultimate (highest) peak force [kN];

- L: Distance between two supporting points (span), equal to $120[\mathrm{~mm}]$;

$K=\frac{D^{3} \times \pi}{32} \times\left(1-\frac{d}{D}\right)$

where:

- $D$ : outer diameter of testing pipes, equal to 21.4 as measured [mm];

- $d$ : inner diameter of testing pipes, equal to 19.5 as measured [mm].
These one-tenth millimeter differences of $d$ and $D$ from the standard are within the tolerance of the caliper. We shall use these measured values in all forthcoming calculations.

The above-mentioned parameters could be categorized into two groups to examine: the first one is a group of primary variables, including the highest peak forces and total displacements of each pipe, and the second one group of secondary variables, including the pipe's elapse-stiffness of pipe phases and slope. Sub-subsections 3.2.1 and 3.2.2 will discuss these two categories.

\subsubsection{The first group}

With respect to direction of the corroded area, in Fig. 12, we can clearly see the highest peak forces of pipes with the patterns of spots arranged in the along direction are always greater than those in the cross direction for all sizes and numbers ( 2 or 3 spots).

A similar trend can be monitored with pipe deformations, with the weaker pipe presenting the larger total displacements. This is applicable to both the sizes and numbers of spots (Fig. 13). Pipes with corroded spots in the cross direction of all sizes (large, medium, small) show a normal rule: the fewer spots, the higher ultimate peak force (Fig. 14). On the other hand, an unexpected trend for pipes with the pattern of along direction is observed as the highest peak forces of medium size spots show the diverse drift, although this is not a major difference (Fig. 15). Likewise, there is a relatively clear tendency when we compare pipes of the same cross pattern with an identical number of spots.

The corroded pipes of larger size with either 2 or 3 spots often exhibit a better ability to withstand loading forces (Fig. 16).To explain this phenomenon, the depth of corroded area (hole depth) was also considered. It was 

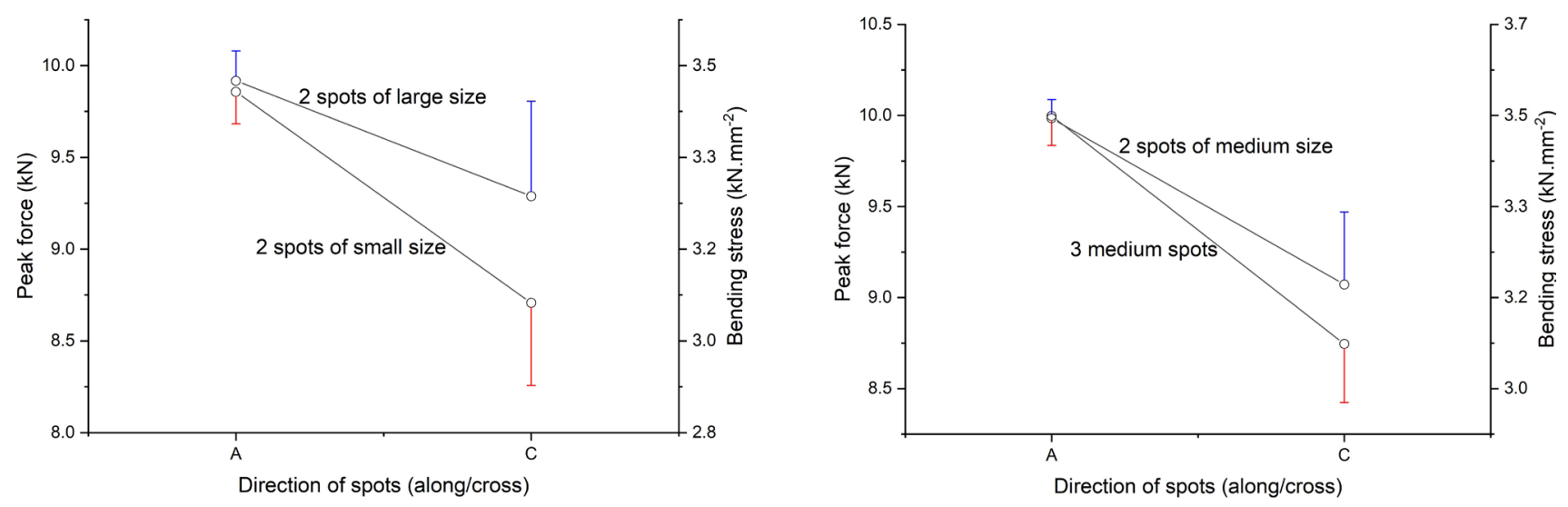

Fig. 12 Trend in highest peak forces for pipes with corroded spots in different arrangements
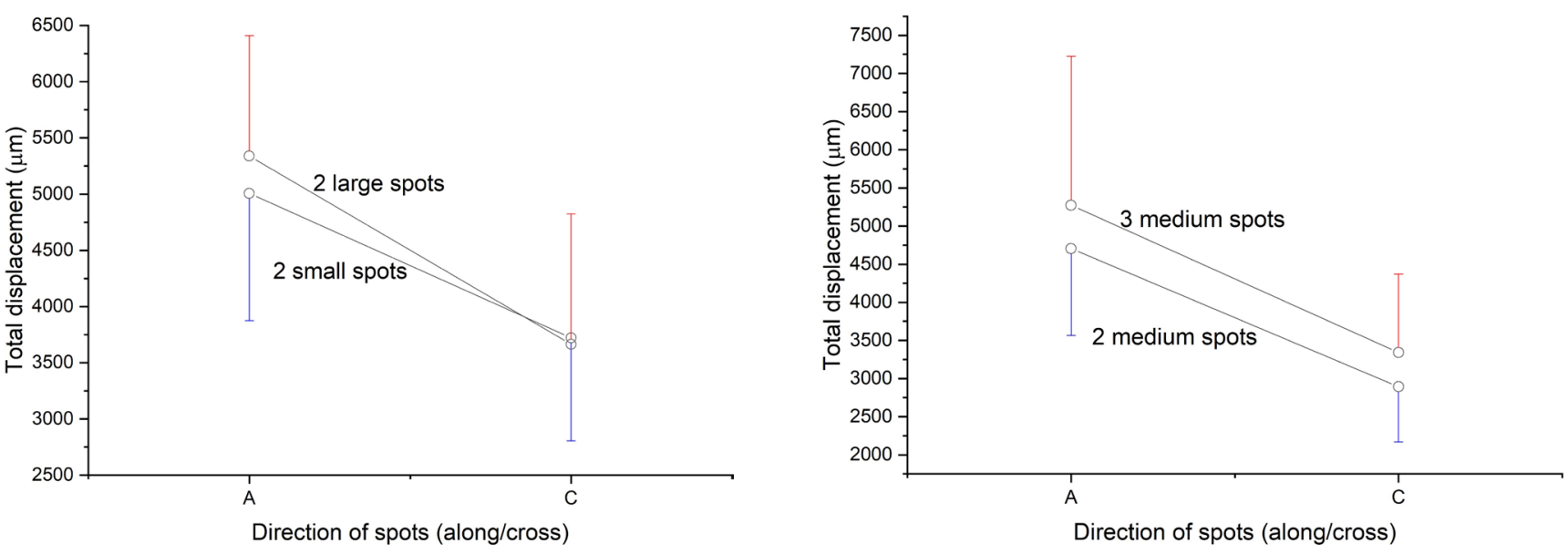

Fig. 13 Trend in total displacements for pipes with corroded spots in different arrangements

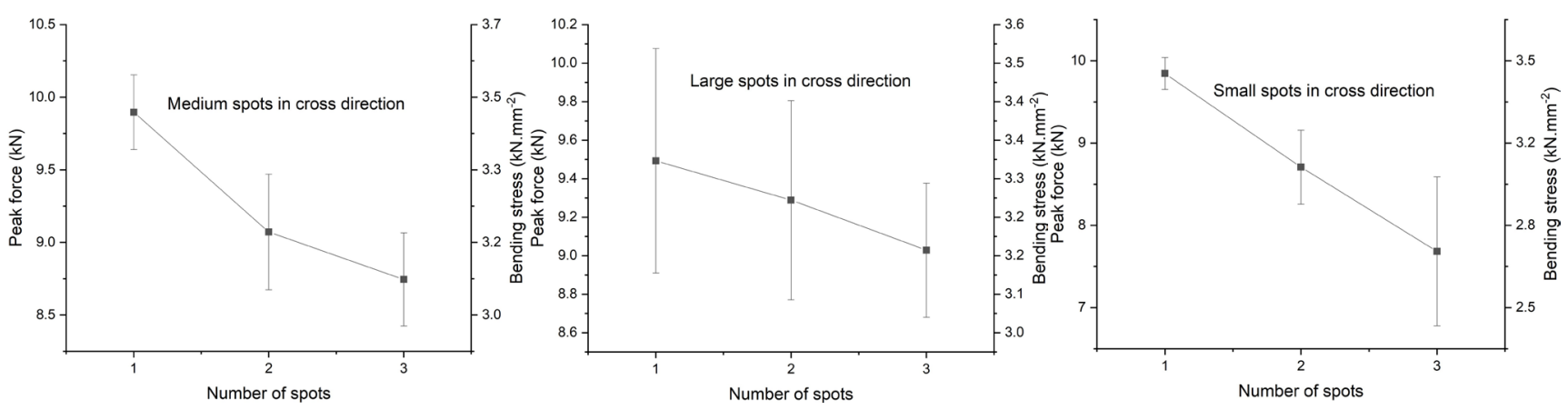

Fig. 14 Trend in highest peak forces for pipes with corroded spots in different arrangements

successfully verified that the smaller the exposed area is, the thinner the pipe wall is at the given spots after the corrosion process and consequently the less remaining strength the pipe has. Hence, the larger total displacement is displayed by the weaker pipes regardless of sizes and numbers of spots. In other words, the smaller the corroded size is or the smaller the number of spots is, the larger deformation the pipes will experience (Fig. 17).

\subsubsection{The second group}

The last comment regarding the relationship between the size, depth of the corroded sites, and the mechanical property of the damaged tubes ought to be seen particularly in certain groups of pipes (Fig. 18).

In order to exclude the bias created by the displacements that resulted from each loading and unloading phase, it is time to adopt two other secondary parameters, which are slope and elapse-stiffness. 


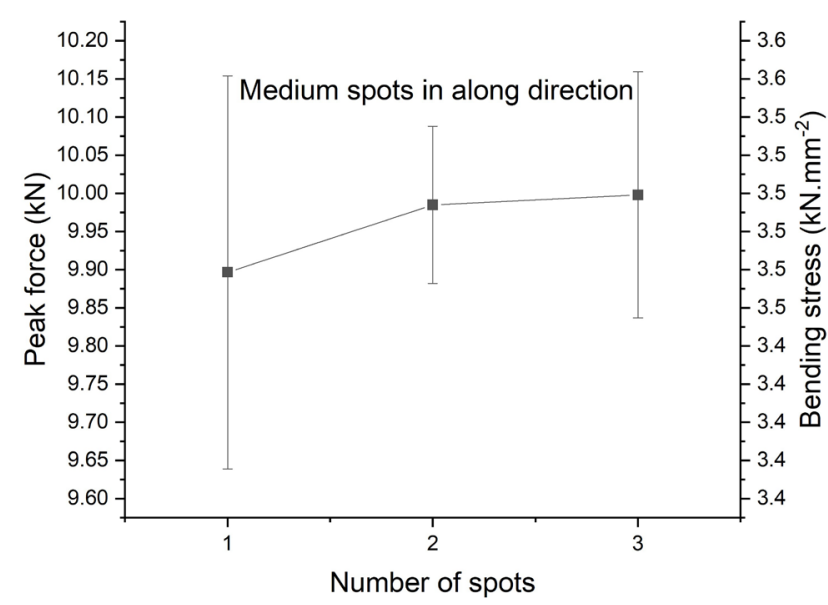

Fig. 15 Noticeable trend in standing peak forces for pipes with corroded spots in different arrangements

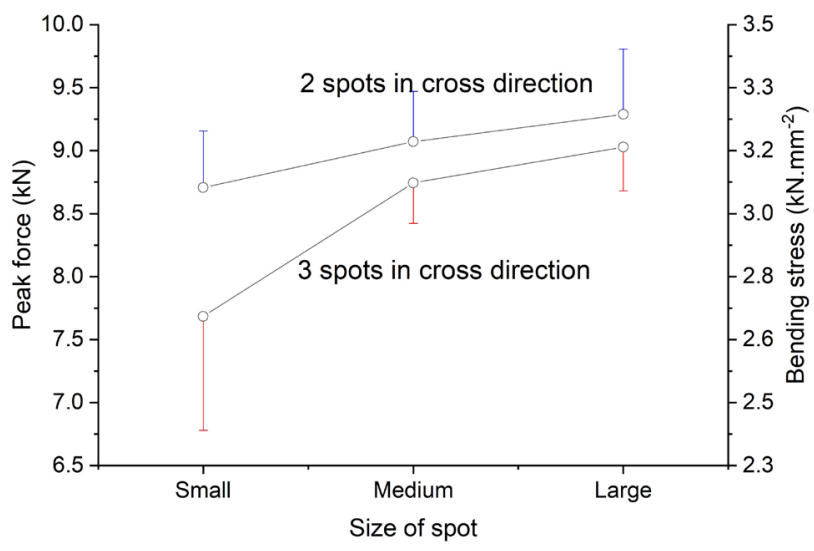

Fig. 16 Noticeable trend in standing peak forces for pipes with corroded spots in different arrangements

Hence, for both of these parameters, the greater value indicates the steeper load-displacement curve, meaning the pipe is stronger than otherwise. It should be noted that in the unloading phase, however, the smaller value of the slope implies higher elasticity of the testing pipe, denoting that the current force has not reached its peak value.
The comparisons of either slope or stiffness between the analogous tubes signify the same message, indicating that the smaller the uncoated area is (the deeper the damage in it is) the weaker the pipe is at that cross section (Fig. 19).

This difference seems to be clearer on those pipes with the spots lying along rather than cross, and surely the damaged pipes with along directional defection always exhibit better mechanical characteristics than those with crossways defection (Fig. 20).

Examining in more detail the relationship between hole depth and other parameters, we recognize a unanimous trend which shows a polynomial dependency of all parameters on hole depth, clarified by Eq. (8):

$y=\frac{A \times x}{x-1.9}$,

where:

- $y$ : Parameter of interest;

- A: Empirical coefficient with corresponding unit assigned by the parameter of interest [-];

- $x$ : Maximum hole depth of the corroded area [mm].

The constant value 1.9 represents the pipe wall thickness $[\mathrm{mm}]$.

Since the fitting curves are all the same, notwithstanding which parameter is examined, the authors call these the attribute parameters associated with the pipe's material. In connection with each loading phase, we may subsequently have a corresponding attributed parameter such as "attributed total dis 68 " indicating the total displacement that happened when we increased the load from $6 \mathrm{kN}$ to $8 \mathrm{kN}$, and likewise with other parameters and loading phases. The illustration of this trend can be seen in Fig. 21. Table 3 lists the fitted values of the empirical coefficient $A$ in different circumstances.

This trend is consistent with the outcome in the work of Tsuji and Meshii [20].
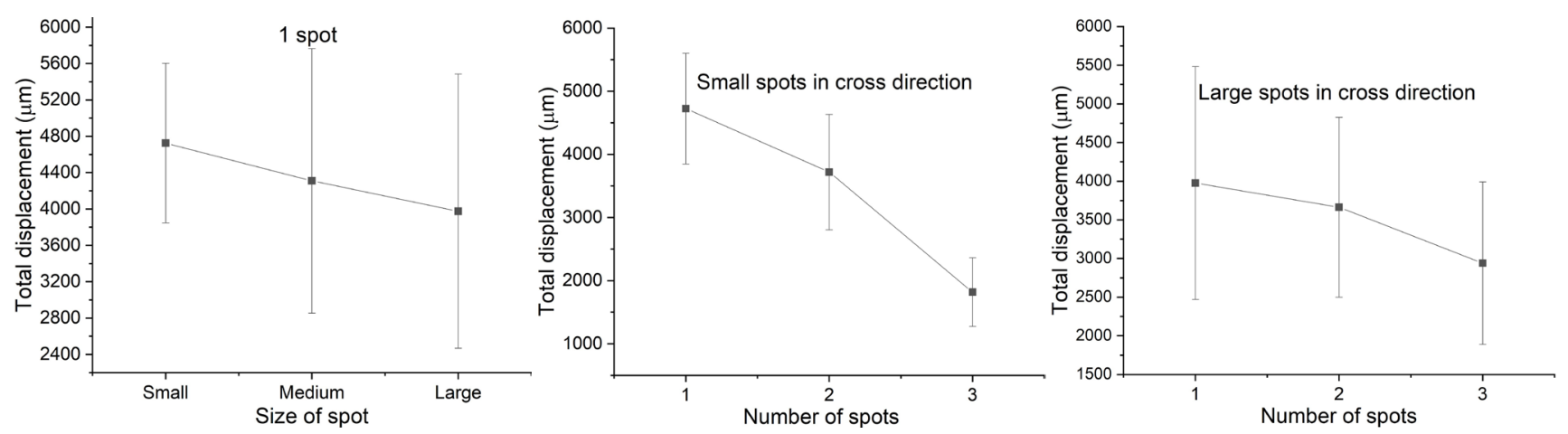

Fig. 17 Noticeable trend in total displacement for pipes with corroded spots in different arrangements 


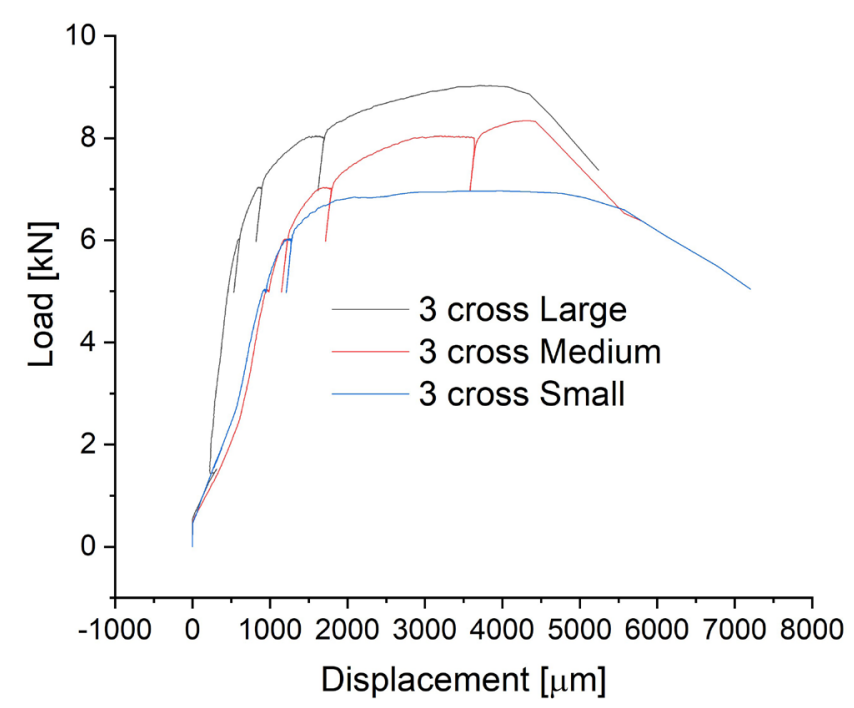

Fig. 18 Load-displacement relationship of a given pipe group

\section{Conclusion}

In accelerated corrosion test: testing severity and extent of testing showed coherent progress of corrosion regardless of quantities of spots, spot directions, or immersion

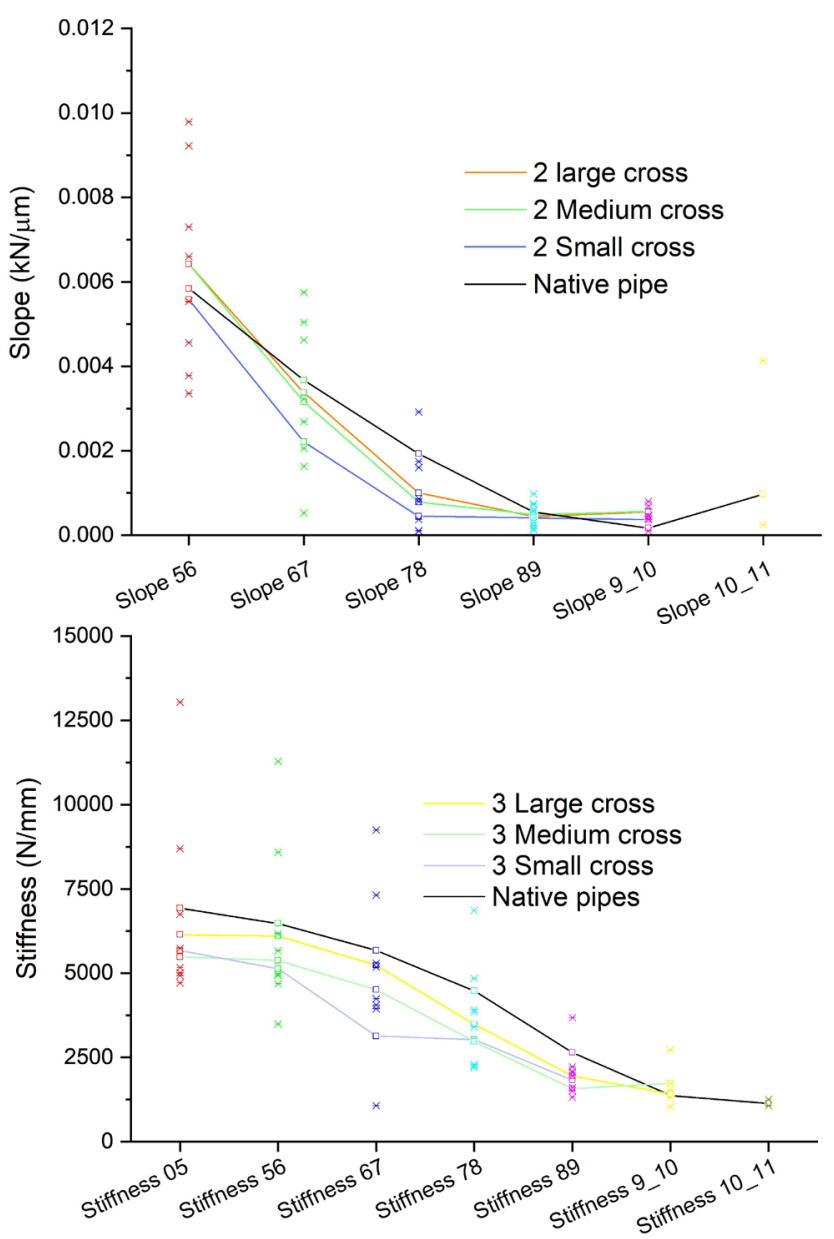

time in a stable temperature condition of the test chamber. The practically identical results of decaying intensity acquired from 82 corrosion tests suggest that the great dependence we could hardly find in this corrosion imitation system is only upon electrolytic liquid variety. The empirical examinations are reproducible and coherent. Accordingly, the applicabilty of this synthetic corrosion installation is verified.

The results of the bending test conducted on pipes with various corroded patterns showed that the pipes with the longitudinal degradation on the outer surface often withstand downward vertical loads better. Put in the same corrosive environment, metallic pipes with less exposed area tend to suffer from deeper damage to the pipe wall, bringing about lower remaining strength. Based on the thickness of the pipe wall left, we can roughly estimate the strength-related indicator of the damaged pipes.

A more detailed inspection of the precise dimensions, geometrical shapes, and depths of corroded sites could be conducted by high-resolution microscopy techniques

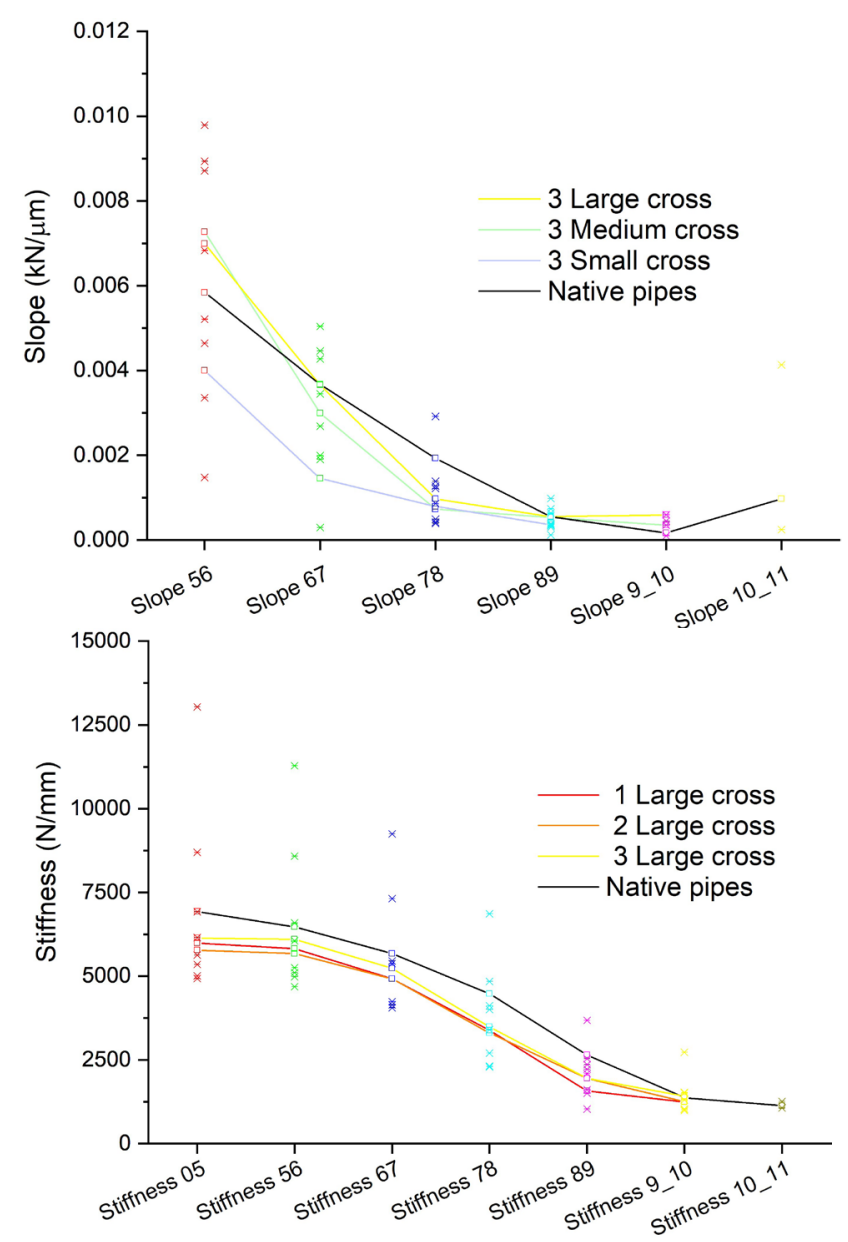

Fig. 19 Slope and stiffness left for pipes with corroded spots in different arrangements 

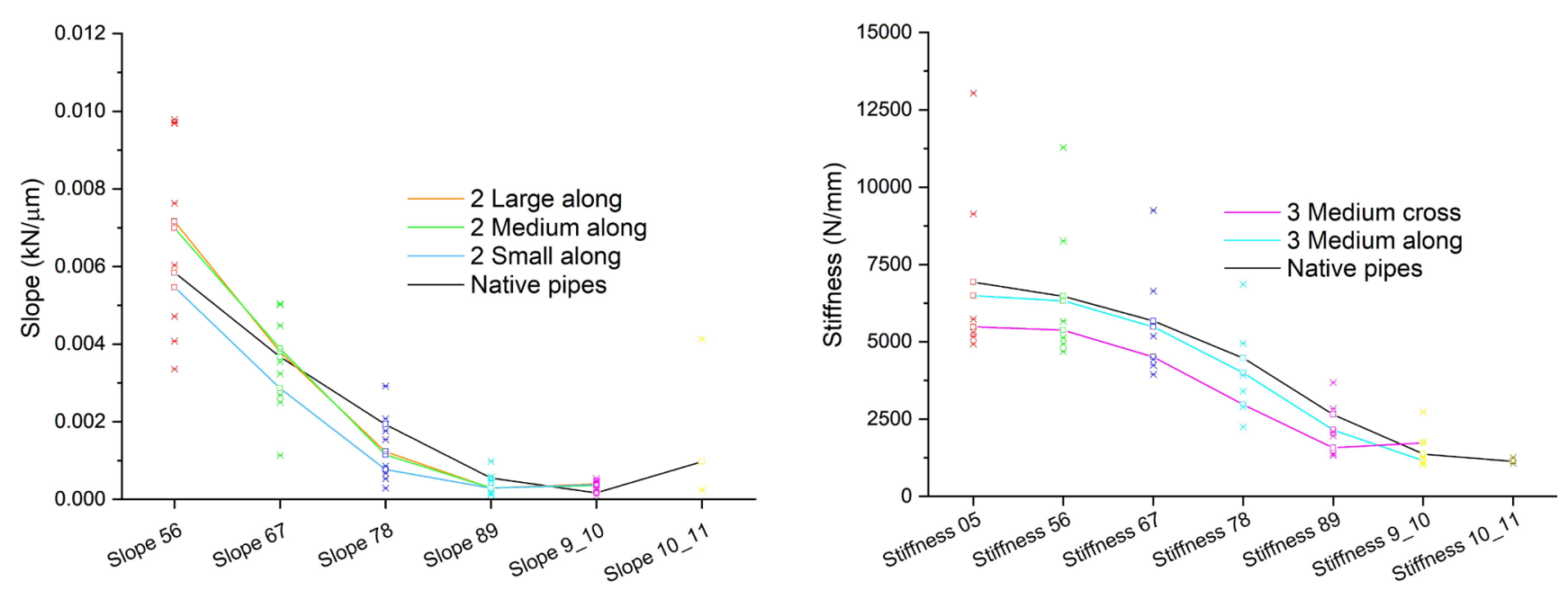

Fig. 20 Slope and stiffness left for pipes with corroded spots in different arrangements

Table 3 Empirical coefficient of diverse parameters

\begin{tabular}{lccc}
\hline $\begin{array}{l}\text { Load step } \\
(\mathrm{kN})\end{array}$ & $\begin{array}{c}\text { Total displacement } \\
(\mathrm{mm})\end{array}$ & $\begin{array}{c}\text { Slope } \\
(\mathrm{kN} / \mathrm{mm})\end{array}$ & $\begin{array}{c}\text { Stiffness } \\
(\mathrm{N} / \mathrm{mm})\end{array}$ \\
\hline $0-5$ & $-855.2 \pm 8.1$ & & $-6430.7 \pm 119.4$ \\
$5-6$ & $-1044.3 \pm 9.7$ & $-7.8 \pm 0.1$ & $-6332.4 \pm 101.3$ \\
$6-5$ & $-971.2 \pm 9.6$ & $-15.2 \pm 0.1$ & \\
$5-7$ & $-1336.3 \pm 14.6$ & $-4.4 \pm 0.07$ & $-5762 \pm 69.3$ \\
$7-6$ & $-1294.6 \pm 15.2$ & $-15.9 \pm 0.15$ & \\
$6-8$ & $-2053.7 \pm 34.5$ & $-1.67 \pm 0.04$ & $-4307.1 \pm 45.8$ \\
$8-7$ & $-1980.4 \pm 34.2$ & $-17.1 \pm 0.16$ & \\
$7-9$ & $-4193.1 \pm 90.7$ & $-0.46 \pm 0.009$ & $-2384.3 \pm 25.6$ \\
$9-8$ & $-4067.6 \pm 87$ & $-18.3 \pm 0.13$ & \\
$8-10$ & $-8397.4 \pm 100$ & $-0.4 \pm 0.007$ & $-1282.6 \pm 16.6$ \\
$10-9$ & $-9913.7 \pm 526.6$ & & \\
\hline
\end{tabular}

to achieve more authoritative data from corroded pipes. Alternative scenarios of aggressive working environments (i.e. different kinds of soils, different electrolyte strengths, etc.) ought to be emulated to shed light on other associated risk factors of pipes. Remaining strength examination on corroded metallic pipes working in various conditions of bedding soils will doubtless produce plenty more educational outcomes with respect to their mechanical debasement.

\section{Acknowledgements}

The research was carried out within the GINOP-2.3.215-2016- 00031 "Innovative solutions for sustainable groundwater resource management" project of the Faculty of Earth Science and Engineering of the University of Miskolc in the framework of the Széchenyi 2020 Plan, funded by the European Union, co-financed by the European Structural and Investment Funds.

We would like to thank our colleagues Mr. András Sebők, Mr. György Czinkota, and Mr. Kövesi Viktor, who worked as our support team, for their help and professional advice in preparing samples and collecting data. Special thanks to the Institute of Environmental Management, the Faculty of Earth Sciences and Engineering at the University of Miskolc for letting us use tools and instruments. 

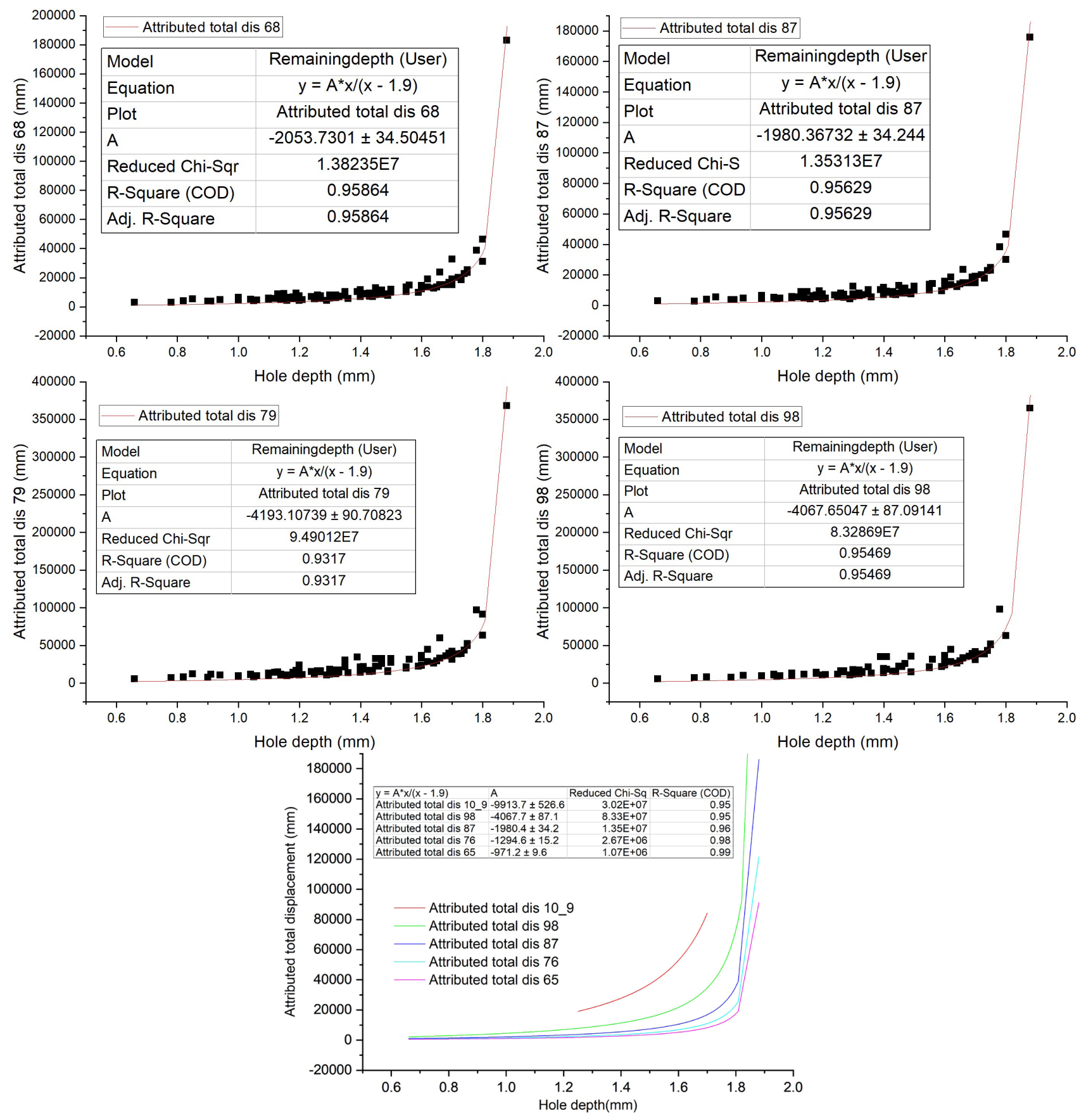

Fig. 21 Attributed parameters' dependency on the hole depth

\section{References}

[1] Perdomo-Díaz, J. J. "Chemical and Electrochemical Conditions on Steel under Disbonded Coating", PhD Thesis, Case Western Reserve University, 1996.

[2] Patkó G. "A Magyar Víziközmű Ágazat bemutatása és 2017. évi statisztikai adatai - MaVíz statisztikai adatgyüjtés" (Presentation of the Hungarian Water Utility Sector and statistical data for 2017 MaVíz statistical data collection), MaVíz, Budapest, Hungary, 2018. (in Hungarian)
[3] Valor, A., Caleyo, F., Hallen, J. M., Velázquez, J. C. "Reliability assessment of buried pipelines based on different corrosion rate models", Corrosion Science, 66, pp. 78-87, 2013. https://doi.org/10.1016/j.corsci.2012.09.005

[4] Khan, F., Howard, R. "Statistical approach to inspection planning and integrity assessment", Insight - Non-Destructive Testing and Condition Monitoring, 49(1), pp. 26-36, 2007. https://doi.org/10.1784/insi.2007.49.1.26 
[5] Maureen, W., Lisa, V. A. A., Lorenzo, V. W. "Corrosion-Related Accidents in Petroleum Refineries: Lessons learned from accidents in EU and OECD countries", Publications Office of the European Union, Luxembourg, Luxembourg, Rep. EUR 26331 EN, 2013. https://doi.org/10.2788/37909

[6] Fővárosi Vízmủvek "Vízcsőhálózat" (Water Pipeline Network), [online] Available at: https://www.vizmuvek.hu/hu/fovarosivizmuvek/tarsasagi-informaciok/vizellatas/vizellatas/ vizcsohalozat [Accessed: 02 October 2019] (in Hungarian)

[7] Masilela Z, Pereira J. "Using the direct current voltage gradient technology as a quality control tool during construction of new pipelines", Engineering Failure Analysis, 5(2), pp. 99-104, 1998. https://doi.org/10.1016/S1350-6307(98)00006-5

[8] Denison, I. A., Romanoff, M. "Corrosion of Galvanized Steels in Soils", Journal of Research of the National Bureau of Standards, 49(5), pp. 299-314, 1952.

https://doi.org/10.6028/jres.049.031

[9] Sadeghi Meresht, E., Shahrabi Farahani, T., Neshati, J. "Failure analysis of stress corrosion cracking occurred in a gas transmission steel pipeline", Engineering Failure Analysis, 18(3), pp. 963-970, 2011.

https://doi.org/10.1016/j.engfailanal.2010.11.014

[10] Li, D. Y., Li, J. C., Zhao, M., Jiang, Q., Wang, J. P. "Failure analysis of some petrochemical plant components", Corrosion Engineering, Science and Technology, 45(6), pp. 461-467, 2010. https://doi.org/10.1179/174327809X397820

[11] Srivastava, S. K., Katarki, M. V., Cherian, V. "Failure analysis of a 30-in subsea oil pipeline", Materials Performance, 47(12), pp. 52-56, 2008. [online] Available at: http://www.materialsperformance. com/magazine/2008/december/failure-analysis-of-a-30-insubsea-oil-pipeline [Accessed: 02 October 2019]

[12] Parnian, N. "Failure analysis of austenitic stainless steel tubes in a gas fired steam heater", Materials \& Design (1980-2015), 36, pp. 788-795, 2012. https://doi.org/10.1016/j.matdes.2011.12.027

[13] Gong, Y., Zhong, J., Yang, Z. G. "Failure analysis of bursting on the inner pipe of a jacketed pipe in a tubular heat exchanger", Materials \& Design, 31(9), pp. 4258-4268, 2010. https://doi.org/10.1016/j.matdes.2010.04.010

[14] Smets, H. M. G., Bogaerts, W. F. L. "Deriving corrosion knowledge from case histories: the neural network approach", Materials \& Design, 13(3), pp. 149-153, 1992. https://doi.org/10.1016/0261-3069(92)90224-6

[15] Nusair Khan, A., Muhammad, W., Salam, I. "Failure analysis of bainitic steel pipe - Failed during cold working process", Materials \& Design (1980-2015), 31(5), pp. 2625-2630, 2010. https://doi.org/10.1016/j.matdes.2009.11.022

[16] Liu, P. F., Zheng, J. Y., Zhang, B. J., Shi, P. "Failure analysis of natural gas buried $\mathrm{X} 65$ steel pipeline under deflection load using finite element method", Materials \& Design, 31(3), pp. 1384-1391, 2010. https://doi.org/10.1016/j.matdes.2009.08.045
[17] Castellanos, V., Albiter, A., Hernández, P., Barrera, G. "Failure analysis expert system for onshore pipelines. Part - I: Structured database and knowledge acquisition", Expert Systems with Applications, 38(9), pp. 11085-11090, 2011.

https://doi.org/10.1016/j.eswa.2011.02.153

[18] Castellanos, V., Albiter, A., Hernández, P., Barrera, G. "Failure analysis expert system for onshore pipelines. Part - II: End-User interface and algorithm", Expert Systems with Applications, 38(9), pp. 11091-11104, 2011.

https://doi.org/10.1016/j.eswa.2011.02.154

[19] Alamilla,J.L.,Sosa,E.,Sánchez-Magaña,C.A.,Andrade-Valencia,R., Contreras, A. "Failure analysis and mechanical performance of an oil pipeline", Materials \& Design, 50, pp. 766-773, 2013.

https://doi.org/10.1016/j.matdes.2013.03.055

[20] Tsuji, M., Meshii, T. "Influence of circumferential flaw length on internal burst pressure of a wall-thinned pipe", Nuclear Engineering and Design, 255, pp. 59-67, 2013. https://doi.org/10.1016/j.nucengdes.2012.10.002

[21] Bony, M., Alamilla, J. L., Vai, R., Flores, E. "Failure Pressure in Corroded Pipelines Based on Equivalent Solutions for Undamaged Pipe", Journal of Pressure Vessel Technology, 132(5), Article Number: 051001, 2010.

https://doi.org/10.1115/1.4001801

[22] Breton, T., Sanchez-Gheno, J.C. Alamilla, J. L., Alvarez-Ramirez, J. "Identification of failure type in corroded pipelines: a Bayesian probabilistic approach", Journal of Hazardous Materials, 179(1-3), pp. 628-634, 2010.

https://oi.org/10.1016/j.jhazmat.2010.03.049

[23] Oliveros, J., Alamilla, J. L, Astudillo, E, Flores, O. "Prediction of Failure Pressures in Pipelines with Corrosion Defects", Journal of Pressure Vessel Technology, 130(2), Article Number: 021703, 2008. https://doi.org/10.1115/1.2892032

[24] Chattopadhyay, J., Dutta, B. K., Kushwaha, H. S. "Experimental and analytical study of three point bend specimen and throughwall circumferentially cracked straight pipe", International Journal of Pressure Vessels and Piping, 77(8), pp. 455-471, 2000. https://doi.org/10.1016/S0308-0161(00)00052-1

[25] European Committee for Standardization "EN 10220:2002 Seamless and welded steel tubes - Dimensions and masses per unit length", CEN, Brussels, Belgium, 2002.

[26] European Committee for Standardization "EN 10217-4:2002 Welded steel tubes for pressure purposes - Technical delivery conditions - Part 4: Electric welded non-alloy steel tubes with specified low temperature properties", CEN, Brussels, Belgium, 2002. 